\title{
Physical dependence on zopiclone: case reports
}

\author{
Ian R Jones, Gary Sullivan
}

Over the past few decades there has been a reluctance to prescribe benzodiazepines for insomnia and anxiety, as evidence for dependence and withdrawal has accumulated. Alternative treatments have therefore been sought.

Zopiclone, a cyclopyrrolone, is chemically unrelated to benzodiazepines but acts via the benzodiazepine $/ \gamma$ aminobutyric acid receptor complex. It is licensed for the short term treatment of insomnia. Claims that zopiclone does not cause rebound, dependence, or withdrawal phenomena may have led to it being considered a safe option for treating insomnia. ${ }^{1}$ We present a series showing evidence of zopiclone dependence and problems caused by withdrawal.

\section{Case reports}

Case 1-A 29 year old man who had had a pneumothorax was prescribed zopiclone $7.5 \mathrm{mg}$ nightly. As he was anxious about a recurrence he increased the dose to $22.5 \mathrm{mg}$ supplemented with tablets from other sources. After eight months he realised he was misusing the drug and stopped taking it suddenly. This resulted in severe anxiety with tachycardia, tremor, sweating, and rebound insomnia. He was treated with amitriptyline $25 \mathrm{mg}$ three times daily for several weeks and made a full recovery.

Case 2-A 26 year old man was prescribed zopiclone $7.5 \mathrm{mg}$ nightly for insomnia. The dose was eventually increased to $7.5 \mathrm{mg}$ four times daily, depending on availability. If he stopped taking zopiclone he experienced anxiety, tremors, sweats, flushes, palpitations, and derealisation. $\mathrm{He}$ was stabilised with $7.5 \mathrm{mg}$ zopiclone nightly and $3.75 \mathrm{mg}$ daily and monitored closely. He described a strong craving for the drug, and attempts to reduce the dose further were firmly resisted.

Case 3-A 49 year old woman received zopiclone $7.5 \mathrm{mg}$ for insomnia during inpatient treatment for depression. She was taking this dose at discharge but subsequently increased it to $15 \mathrm{mg}$ and then $22.5 \mathrm{mg}$. She remained on $22.5 \mathrm{mg}$ one year later. She had tried to stop taking zopiclone twice but experienced severe rebound insomnia and anxiety. She was therefore reluctant to reduce the dose.

Case 4-A 36 year old woman with bipolar affective disorder was prescribed zopiclone $7.5 \mathrm{mg}$ nightly for insomnia. The following year she was taking $7.5 \mathrm{mg}$ four times daily, obtaining supplies by changing doctors. If she reduced her intake suddenly she experienced sweating, palpitations, tremor, and anxiety. Her intake was monitored and the dose was gradually reduced. She had been dependent on benzodiazepines although these were stopped before zopiclone was prescribed. She had no history of alcohol dependence.

\section{Comment}

All these patients increased their intake of zopiclone above the dose initially prescribed and their withdrawal symptoms included craving, anxiety, and insomnia. Although it has been suggested that zopiclone is not associated with dependence or withdrawal phenomena, rebound insomnia was experienced by normal volunteers after taking the drug for only two weeks. ${ }^{2}$ One case of zopiclone dependence has been reported, although this was complicated by a misuse of benzodiazepines and alcohol. ${ }^{3}$ From our series it would seem that dependence is not restricted to people with a history of benzodiazepine or alcohol misuse, as this applied to only one of our patients. The potential for zopiclone misuse has also been reported in three cases. ${ }^{4}$

Studies of up to four weeks of zopiclone use have not demonstrated evidence of dependence or withdrawal problems. ${ }^{5}$ Our cases reveal problems with use over a considerably longer period which may more closely resemble clinical practice.

Though zopliclone is a safe and effective treatment for insomnia in the short term, it seems that it can cause dependence with long term use. It would seem reasonable to apply the same caution to prescribing this drug that is applied to the benzodiazepines. Its use should be limited to the short term indications for which it is licensed.

Contributors: Both authors were involved in finding the patients, performing the literature review, and writing the paper. Funding: IRJ is supported by a grant from the Wellcome Trust.

Conflict of interest: None.

1 Bianchi M, Musch B. Zopiclone discontinuation: review of 25 studies assessing withdrawal and rebound phenomena. Int Clin Psychopharmacol 1990;5(suppl 2):139-45.

2 Lader M, Frecka G. Subjective effects during and on discontinuation of zopiclone and of temazepam in healthy subjects. Pharmacopsychiatry 1987;20:67-71.

3 Thakore J, Dinan TG. Physical dependence following zopiclone usage: a case report. Hum Psychopharmacol 1992;7:143-5.

4 Sullivan G, McBride AJ, Clee WB. Zopiclone abuse in South Wales: three case reports. Hum Psychopharmacol 1995;10:351-2.

5 Wadworth AN, McTavish D. Zopiclone: a review of its pharmacological properties and therapeutic efficacy as an hypnotic. Drugs and Aging 1993;3:441-59.

(Accepted 25 April 1977)

\section{One hundred years ago}

\section{A marriage examining board}

A reformer in the Ohio Legislature has introduced a Bill requiring persons applying for marriage licences to pass a medical examination. The Bill forbids the issue of a licence to any person suffering from dipsomania, insanity, or tuberculosis. It provides for a marriage examining Board of three physicians in each county. A measure of this kind has been advocated by many reformers of society from Sir Thomas More down to our own day, but if science is strong human nature is stronger. It is pretty certain that love which laughs at locksmiths will not show more respect for medical certificates. (BMJ 1898;i:582)
Division of Psychological Medicine,

University of Wales College of Medicine, Cardiff CF4 4XN

Ian R Jones, clinical research fellow Gary Sullivan, senior registrar

Correspondence to: Dr Jones jonesir2@cf.ac.uk

BMJ 1998;316:117 